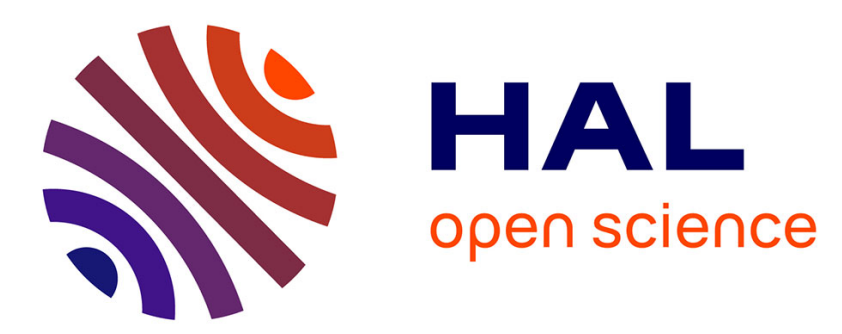

\title{
Urban Road Traffic Fuel Consumption Optimization via Variable Speed Limits or Signalized Access Control: A Comparative Study
}

Bassel Othman, Giovanni de Nunzio, Domenico Di Domenico, Carlos Canudas de Wit

\section{To cite this version:}

Bassel Othman, Giovanni de Nunzio, Domenico Di Domenico, Carlos Canudas de Wit. Urban Road Traffic Fuel Consumption Optimization via Variable Speed Limits or Signalized Access Control: A Comparative Study. CDC 2021 - 60th IEEE Conference on Decision and Control, Dec 2021, Austin, Texas, United States. pp.1-6, 10.1109/CDC45484.2021.9683194 . hal-03361310

\author{
HAL Id: hal-03361310 \\ https://hal.science/hal-03361310
}

Submitted on 1 Oct 2021

HAL is a multi-disciplinary open access archive for the deposit and dissemination of scientific research documents, whether they are published or not. The documents may come from teaching and research institutions in France or abroad, or from public or private research centers.
L'archive ouverte pluridisciplinaire HAL, est destinée au dépôt et à la diffusion de documents scientifiques de niveau recherche, publiés ou non, émanant des établissements d'enseignement et de recherche français ou étrangers, des laboratoires publics ou privés. 


\title{
Urban Road Traffic Fuel Consumption Optimization via Variable Speed Limits or Signalized Access Control: A Comparative Study
}

\author{
Bassel Othman, Giovanni De Nunzio, Domenico Di Domenico, and Carlos Canudas-de-Wit
}

\begin{abstract}
This work focuses on comparing the ecological potential of variable speed limits (VSLs) and signalized access control. A synthetic two-region network composed of an urban and a peri-urban area is considered. This study aims at improving the energy efficiency in both areas. A microscopic traffic simulator (SUMO) is used to model the dynamics of the system. It is controlled by a nonlinear model predictive control (NMPC) framework based on a macroscopic traffic model, which is an adapted version of the cell transmission model (CTM). The controller is coupled with an artificial neural network (ANN) to predict the fuel consumption. Finally, microscopic physical energy and $\mathrm{NO}_{\mathrm{X}}$ models are used to evaluate the performance of both control actuators. The results reveal that VSLs are more promising due to the smoother variation of the densities.
\end{abstract}

\section{INTRODUCTION}

Epidemiological research has highlighted that mortality and several cardiovascular and respiratory diseases are highly correlated with air pollution. A study conducted in 30 countries revealed that $\mathrm{PM}_{2.5}$ concentrations above minimum exposure levels were responsible for $22 \%$ of infant deaths [1]. Although traffic related pollutants $\left(\mathrm{NO}_{2}, \mathrm{NO}_{\mathrm{X}}, \mathrm{PM}_{10}\right.$, and $\mathrm{PM}_{2.5}$ ) have been on a downward trend in major cities since 2010 due to more efficient vehicles, pollution levels remain well above the recommended European limit value [2]. To improve air quality in urban areas, the development of new engine technologies can be combined with connectivitybased solutions [3] and a change of individual habits induced by public authorities [4].

Although most variable speed limit (VSL) approaches in urban areas are not energy-efficiency oriented [5], [6], [7], speed limits have a strong impact on energy consumption and pollutant emission because of their impact on traffic dynamics [8]. In this sense, ecological VSL strategies are promising in urban environments as they can adapt to the traffic demand [9], [10]. However, studies that focus on the control of urban networks usually overlook the performance in the peri-urban areas.

The use of signalized access control actuators to optimize the flow of vehicles between different areas of a network is a well-known subject in the literature [11], [12]. These approaches usually focus on developing control systems

\footnotetext{
Bassel Othman, Giovanni De Nunzio, and Domenico $\mathrm{Di}$ Domenico are with IFP Energies nouvelles, Rondpoint de l'échangeur de Solaize, BP 3, 69360 Solaize, France \{bassel.othman, giovanni.de-nunzio, domenico.didomenico\}eifpen.fr

Bassel Othman and Carlos Canudas-de-Wit are with Grenoble Alpes University, CNRS, Inria, Grenoble INP, GIPSA-lab, 38000 Grenoble, France carlos.canudas-de-witegipsa-lab.fr
}

for efficient congestion management in large-scale urban networks.

In this study, we propose to consider a synthetic road network of intermediate size consisting of a peri-urban and an urban area. The objective is to analyze the impact of VSLs and signalized access control on energy efficiency, pollutant emissions, and traffic performance. To achieve this, a nonlinear model predictive control (NMPC) framework is implemented with either the speed limits or the signalized accesses as actuators. The controller considers an adapted version of the cell transmission model (CTM) to evaluate the traffic dynamics, and an artificial neural network (ANN) is used to predict the global energy consumption in the network. To evaluate the performance of both controllers, simulations are run with a microscopic traffic simulator (SUMO), and the energy consumption and pollutant emissions are calculated with a physical model.

The main contributions of this paper are:

- A comparison of the effect on energy efficiency of two control actuators, namely the speed limits and the signalized access actuators, is realized. Both actuators are controlled in an NMPC framework that has the same parameterization.

- The CTM is adapted in order to be consistent with traffic light signals (TLS) and to consider additional endogenous demands inside the network.

The body of this paper is organized as follows. Section II presents the problem setting. Section III describes the optimal control strategies. The results are presented in Section IV. Finally, Section V contains concluding remarks.

\section{PROBLEM SETTING}

This study considers a road network composed of a periurban $(\mathcal{B})$ and an urban $(\mathcal{A})$ area, as represented in Fig. 1. It aims to compare the potential energy efficiency impact of

- VSL control in the urban area $\mathcal{A}$,

- signalized access control from the peri-urban $\mathcal{B}$ to the urban $\mathcal{A}$ area.

To be more representative of the traffic dynamics, vehicles are generated upstream from the peri-urban area (constant exogenous demand $d^{\text {in }}$ ) and within the urban area through parking lots for example (intermittent endogenous demand $d_{i}(k)$, where $i$ denotes the cell and $k$ is the time step). As represented in Fig. 1, the vehicles all have destinations downstream from the urban area (vehicle sinks of supply $s^{\text {out }}$ ). Note that in this study, the parking lots described above are considered as sources only. In a future work, parking lots and households could also behave as vehicle sinks. 


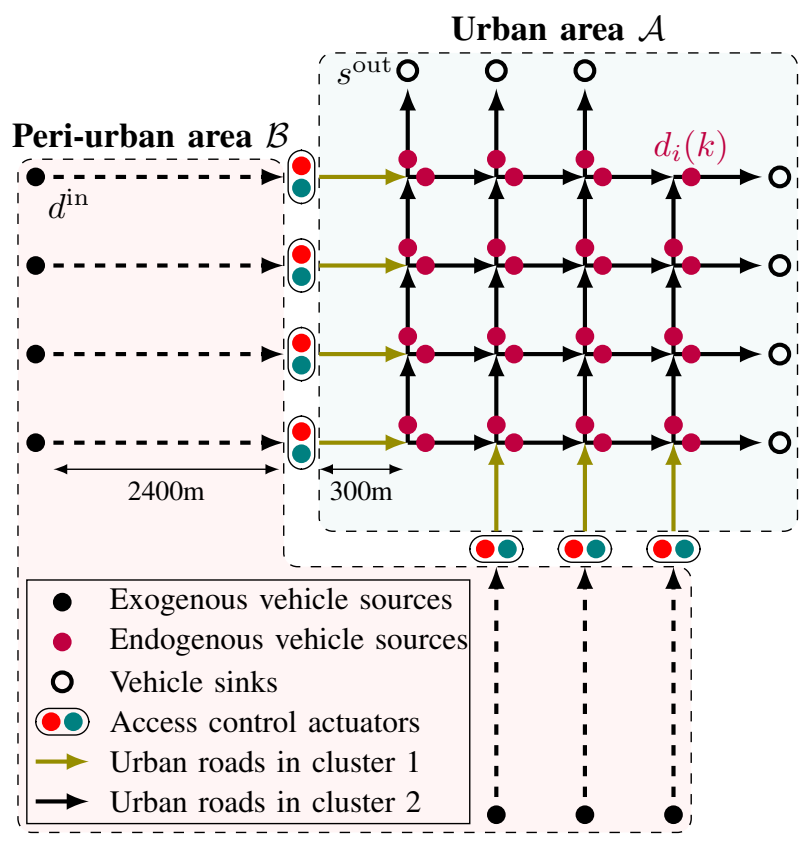

Fig. 1: Representation of the road network and the access control actuators. The urban area corresponds to the solid line roads and the peri-urban area is represented by the dashed line roads.

In this work, the objective is to improve the energy efficiency in both areas. To achieve this, an optimal regulation of the flow of vehicles through the network is necessary, either through VSLs or access control from the peri-urban to the urban area.

\section{A. Traffic model}

In order to model traffic dynamics, we use the cell transmission model (CTM) [13], which is a temporal and spatial discretization of the Lighthill-Whitham-Richards (LWR) model [14], [15]. The road network under consideration is discretized into 60-meter-long cells. Based on the conservation of the number of vehicles, the density in cell $i$ at time step $k+1$ is

$$
\rho_{i}(k+1)=\rho_{i}(k)+\frac{\delta_{t}}{\delta_{x}}\left(\varphi_{i}^{\text {in }}(k)-\varphi_{i}^{\text {out }}(k)\right)
$$

where $\varphi_{i}^{\text {in }}$ and $\varphi_{i}^{\text {out }}$ denote respectively the inflow and the outflow of cell $i$. The parameters $\delta_{t}$ and $\delta_{x}$ are respectively the time step duration and the cell length. In this framework, the densities $\rho$ characterize the state of the system.

The sets of cells $\mathcal{A}$ and $\mathcal{B}$ consist respectively of the cells of the urban and the peri-urban areas. To characterize the road connections, sets $\mathcal{P}_{i}$ and $\mathcal{N}_{i}$ are associated with each cell $i$. They correspond respectively to the upstream and the downstream cells connected to $i$. The function $|$.$| returns the$ number of cells in each set. A few illustrating examples are given in Table I. Moreover, we define $\mathcal{C} \subset \mathcal{B}$ as the set of peri-urban cells that are at the interface with the urban area. In this work, access control actuators are located at the downstream end of cells $\mathcal{C}$. Their behavior is characterized by the green function $g$ defined as follows

$$
g(k)= \begin{cases}1, & \text { if } k \leq\left\lfloor\frac{k}{T_{\text {cycle }}}\right\rfloor+\kappa T_{\text {cycle }} \\ 0, & \text { otherwise }\end{cases}
$$

where the duty cycle $\kappa$ takes on continuous values between 0 (closed access) and 1 (open access), and is defined as

$$
\kappa=\frac{T_{\text {green }}}{T_{\text {cycle }}}
$$

TABLE I: Examples of cells connections.

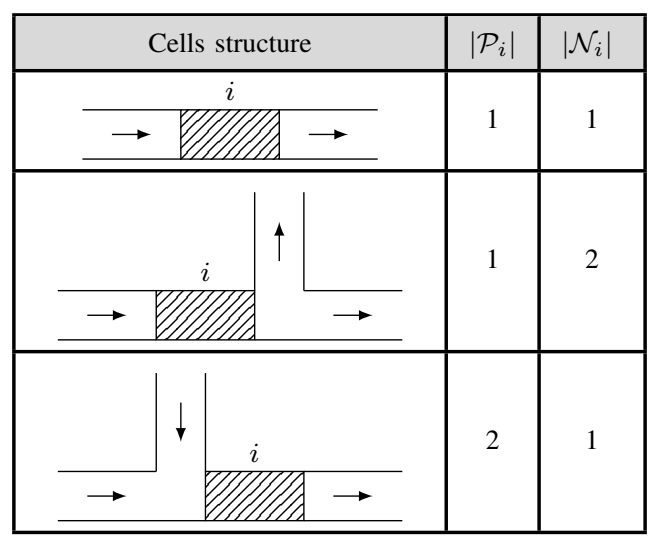

The expression of the cells inflows and outflows depends on the number of upstream and downstream connections. For example, to calculate the flows at an intersection in the urban area, it is essential to take into account the split ratios $\beta_{i}$, as well as the behavior of TLS, which are fixed and characterized by binary green functions $\alpha_{i}$. Based on the trapezoidal fundamental diagram introduced in [13], the possible expressions are summarized in Table II, where the demand and supply functions are respectively defined as

$$
\begin{aligned}
D_{i}(k) & =V_{i} \rho_{i}(k)+d_{i}(k) \\
S_{i}(k) & =w\left(\rho^{\mathrm{M}}-\rho_{i}(k)\right)
\end{aligned}
$$

The fundamental diagram parameters $V_{i}, \varphi_{i}^{\mathrm{M}}, w$, and $\rho^{\mathrm{M}}$ denote respectively the speed limit, the maximum flow, the backward wave speed, and the maximum density. Based on the trapezoidal fundamental diagram, the average speed in each cell can be calculated as follows

$$
v_{i}(k)=\min \left\{V_{i}, \frac{\varphi_{i}^{\mathrm{M}}}{\rho_{i}(k)}, w \frac{\rho^{\mathrm{M}}-\rho_{i}(k)}{\rho_{i}(k)}\right\}
$$

Finally, the total travel distance (TTD) is defined in each area over a simulation period $T$ as

$$
\begin{aligned}
T T D_{\mathcal{A}}^{1 \rightarrow T} & =\delta_{t} \delta_{x} \sum_{i \in \mathcal{A}} \sum_{k=1}^{T} \rho_{i}(k) v_{i}(k) \\
T T D_{\mathcal{B}}^{1 \rightarrow T} & =\delta_{t} \delta_{x} \sum_{i \in \mathcal{B}} \sum_{k=1}^{T} \rho_{i}(k) v_{i}(k)
\end{aligned}
$$


TABLE II: Expression of cells outflows and inflows, depending on the number of upstream and downstream connections.

\begin{tabular}{|c|c|}
\hline$\left|\mathcal{N}_{i}\right|$ & Expression of $\varphi_{i}^{\text {out }}(k)$ \\
\hline 0 & $\min \left\{D_{i}(k), \varphi_{i}^{\mathrm{M}}, s^{\text {out }}(k)\right\}$ \\
\hline 1 & $\begin{array}{l}\text { If } i \in \mathcal{C}: \\
g(k) \times \min \left\{D_{i}(k), \varphi_{i}^{\mathrm{M}}, S_{\mathcal{N}_{i}}(k)\right\} \\
\frac{\text { Else: }}{\min }\left\{D_{i}(k), \varphi_{i}^{\mathrm{M}}, S_{\mathcal{N}_{i}}(k)\right\}\end{array}$ \\
\hline$\geq 2$ & $\alpha_{i}(k) \min \left\{D_{i}(k), \varphi_{i}^{\mathrm{M}},\left\{\frac{S_{j}(k)}{\beta_{j}}\right\}_{j \in \mathcal{N}_{i}}\right\}$ \\
\hline$\left|\mathcal{P}_{i}\right|$ & Expression of $\varphi_{i}^{\text {in }}(k)$ \\
\hline 0 & $\min \left\{d^{\mathrm{in}}(k), \varphi_{i}^{\mathrm{M}}, S_{i}(k)\right\}$ \\
\hline 1 & 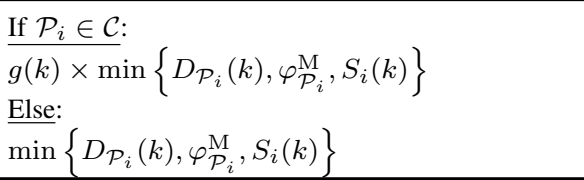 \\
\hline$\geq 2$ & $\beta_{i} \sum_{j \in \mathcal{P}_{i}} \alpha_{j}(k) \min \left\{D_{j}(k), \varphi_{j}^{\mathrm{M}},\left\{\frac{S_{l}(k)}{\beta_{l}}\right\}_{l \in \mathcal{N}_{j}}\right\}$ \\
\hline
\end{tabular}

\section{B. Energy model}

To predict fuel consumption, the calibration of an ANN is preferred to the use of existing macroscopic energy models. First, it captures the impact of density and average speed variations without the constraint of introducing a macroscopic acceleration (defined as the discrete derivative of the average speed), which would be strongly linked to the simulation step [16]. Then, the ANN has a greater sensitivity to fuel overconsumption at low average speeds. Finally, this ensures that the energy model is adapted to the type of vehicle and the network topology under consideration. However, it is essential to keep in mind that this ANN-based model may not be adapted to all types of networks, vehicles, and driving styles.

The proposed ANN predicts the average fuel consumption rate per vehicle in cell $i$ at time $k$, expressed in liters per second per vehicle and denoted $y_{i}^{k}$. It is composed of three hidden layers, whose nodes use the rectifier activation function that returns the positive part of its argument. The training data are obtained by microscopic simulation performed in the road network presented in Fig. 1. It is then processed by a microscopic physical energy model (cf. Section III-A), considering Euro 4 diesel passenger cars. Two initial density levels $\left(0 \%\right.$ and $70 \%$ of the maximum density $\left.\rho^{\mathrm{M}}\right)$, and four different constant speed limits $(20 \mathrm{~km} / \mathrm{h}, 30 \mathrm{~km} / \mathrm{h}, 40 \mathrm{~km} / \mathrm{h}$, $50 \mathrm{~km} / \mathrm{h}$ ) are considered in the simulations. The data are measured at a sampling frequency of $1 \mathrm{~Hz}$, generating about 3.5 million data points.

The ANN inputs can be listed as follows

$$
y_{i}^{k}=f\left(\rho_{i}(k), \rho_{i}(k-1), v_{i}(k), v_{i}(k-1), V_{i}, \alpha_{i}(k)\right)
$$

They include the densities and speeds at current and previous time steps, the speed limit, and the TLS state. In case cell $i$ is not regulated by a TLS, we consider $\forall k, \alpha_{i}(k)=1$. The densities and speeds at previous time steps are included in the model inputs as they add information on the dynamics of the system. This partially compensates for the fact that the macroscopic CTM variables do not contain any information on vehicles accelerations.

Finally, the total fuel consumption in areas $\mathcal{A}$ and $\mathcal{B}$ over a simulation period $T$ are calculated as follows

$$
\begin{aligned}
& E_{\mathcal{A}}^{1 \rightarrow T}=\delta_{t} \delta_{x} \sum_{i \in \mathcal{A}} \sum_{k=1}^{T} \rho_{i}(k) y_{i}^{k} \\
& E_{\mathcal{B}}^{1 \rightarrow T}=\delta_{t} \delta_{x} \sum_{i \in \mathcal{B}} \sum_{k=1}^{T} \rho_{i}(k) y_{i}^{k}
\end{aligned}
$$

\section{OPTIMAL CONTROL}

In this section, we present the energy-oriented optimization problem and we detail the two proposed approaches to solve it.

\section{A. Model predictive control}

To control the system, we propose to implement an NMPC framework because the traffic dynamics is corrected at each control iteration. The associated block diagram is given in Fig. 2.

The dynamics of the controlled system is modeled using a microscopic traffic simulator, namely SUMO [17], with the car-following intelligent driver model (IDM) [18]. To calibrate the maximum acceleration $a$ and comfortable deceleration $b$ of vehicles, real-world driving data collected in French cities are used. This is particularly useful as very different values can be found in the literature for these parameters. In practice, the speed profiles of 648 journeys have been recorded at a sampling frequency of $1 \mathrm{~Hz}$ using the drivers' smartphones. In order to reduce the influence of outliers (unusual driving behaviors, other means of transportation such as motorbikes, measurement errors), the $1 \%$ highest accelerations and the $1 \%$ highest decelerations are filtered out, resulting in $a=2.4 \mathrm{~m} . \mathrm{s}^{-2}$ and $b=2.8 \mathrm{~m} . \mathrm{s}^{-2}$. Note that the calibration of the comfortable deceleration $b$ is not of primary importance in the sense that vehicles can always perform emergency brakings (up to $9 \mathrm{~m} . \mathrm{s}^{-2}$ ) in order to avoid crashes, to stop at a red TLS, etc. Also, the impact of $b$ on the vehicles' energy consumption and pollutant emission is smaller than the one of $a$, as vehicles' energy efficiency mostly depends on acceleration phases. The other IDM parameters are set to standard values, namely $s_{0}=2 \mathrm{~m}$, $\delta=4, \tau=1 \mathrm{~s}, v_{0}=50 \mathrm{~km} / \mathrm{h}[18]$.

Additionally, microscopic physical energy and $\mathrm{NO}_{\mathrm{X}}$ models are introduced to evaluate the performance of the controller. These models calculate the wheel force and torque by using Newton's second law of motion and expressing the resistive forces. Based on the vehicle's speed and gear ratio, it is then possible to calculate the engine torque and speed. Finally, a two-dimensional map is used to obtain the fuel consumption rate as a function of the engine torque and speed. The $\mathrm{NO}_{\mathrm{X}}$ emission rate is calculated using a linear 
regression of the burned gas rate (obtained from another twodimensional map of the engine torque and speed) and the in-cylinder fuel mass per stroke and displaced volume [19].

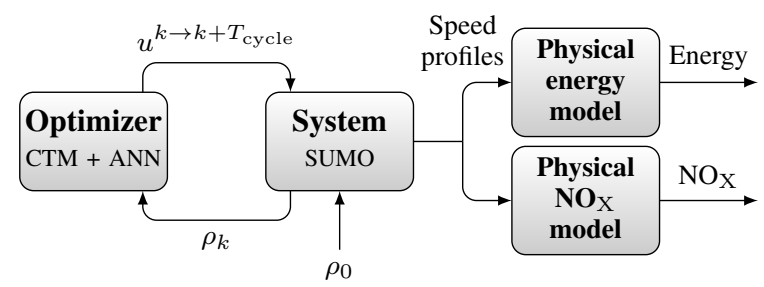

Fig. 2: Block diagram of the NMPC approach.

In this study, the average fuel consumption per vehicle and per distance, expressed in liters per 100 kilometers, is a metric of particular interest because minimizing it ensures a global improvement of the energy efficiency. It can be defined as the ratio of the energy consumption and the TTD. The objective function to minimize is the weighted sum of the average energy in each area, as follows

$$
J^{1 \rightarrow T}=\lambda \frac{E_{\mathcal{A}}^{1 \rightarrow T}}{\theta_{\mathcal{A}} T T D_{\mathcal{A}}^{1 \rightarrow T}}+(1-\lambda) \frac{E_{\mathcal{B}}^{1 \rightarrow T}}{\theta_{\mathcal{B}} T T D_{\mathcal{B}}^{1 \rightarrow T}}
$$

where $\theta_{\mathcal{A}}$ and $\theta_{\mathcal{B}}$ are normalization coefficients, and $\lambda$ is a weighting coefficient. The two terms are normalized because the fuel consumption rates can be very different in both areas due to the presence of TLS and to different speed limits. In this sense, the actuators seek to obtain a compromise of the energy efficiency between both areas.

To reduce the computational complexity due to the large size and the non-linearity of the problem, the control is updated every $T_{\text {cycle }}$, and the optimizer finds a piecewise constant control over the prediction horizon $T_{\mathrm{p}}$. The parameterization of the controller is summarized in Fig. 3. For illustration purposes, the diagram is realized with $T_{\mathrm{p}}=$ $3 T_{\text {cycle }}$. In this study, we actually consider $T_{\mathrm{p}}=5 T_{\text {cycle }}$.

\section{B. Variable speed limits}

In this approach, the control actuators correspond to the speed limits $V_{i}$ inside the urban area. They appear explicitly in equations $4 \mathrm{a}, 5$, and 7 of the model. In order to reduce the number of control variables, and because of the high symmetry of the network under consideration, we propose to define two clusters of roads that have common speed limits. As indicated in Fig. 1, the first cluster is composed of the roads entering the urban area (speed limit $V_{1}$ ). The second cluster is composed of the inner urban roads (speed limit $V_{2}$ ). Hence, the controller solves the following problem at each control iteration $k$
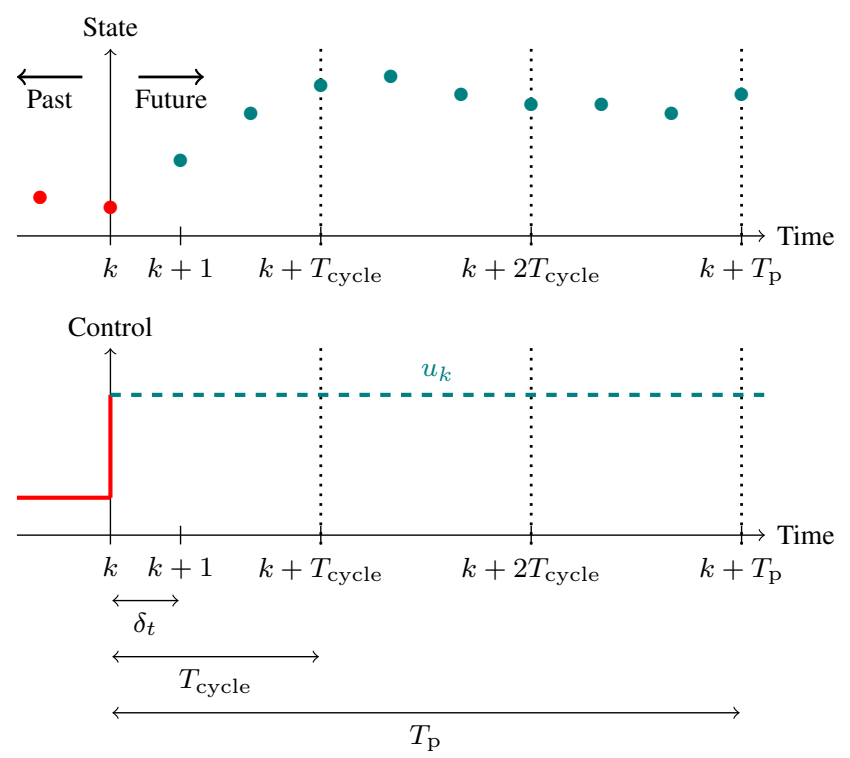

Fig. 3: Representation of the NMPC framework, for $T_{\mathrm{p}}=3 T_{\text {cycle. }}$.

$$
\begin{array}{ll}
\min _{V_{1}, V_{2}} & J^{k \rightarrow k+T_{\mathrm{p}}}\left(\rho, V_{1}, V_{2}\right) \\
\text { s.t. } & \rho_{i}(e+1)=\rho_{i}(e)+\frac{\delta_{t}}{\delta_{x}}\left(\varphi_{i}^{\text {in }}(e)-\varphi_{i}^{\text {out }}(e)\right), \\
& \forall e \in\left[k, \ldots, k+T_{\mathrm{p}}-1\right] \\
& V 1, V 2 \in[20,50] \mathrm{km} / \mathrm{h}
\end{array}
$$

\section{Access control}

In this approach, the control actuators are the access points between the peri-urban and the urban area, whose behavior is characterized by the duty cycle $\kappa$. This control actuator appears explicitly in equation 2 and in the expressions of flows in Table II. Due to the network symmetry and the fact that the exogenous demands are all equal, we propose to control all the access points with the same control variable. Therefore, the controller solves the following problem at each control iteration $k$

$$
\begin{array}{ll}
\min _{\kappa} & J^{k \rightarrow k+T_{\mathrm{p}}}(\rho, \kappa) \\
\text { s.t. } & \rho_{i}(e+1)=\rho_{i}(e)+\frac{\delta_{t}}{\delta_{x}}\left(\varphi_{i}^{\text {in }}(e)-\varphi_{i}^{\text {out }}(e)\right), \\
& \forall e \in\left[k . . k+T_{\mathrm{p}}-1\right] \\
& \kappa \in[0,1]
\end{array}
$$

The fact that the controller optimizes the duty cycle $\kappa$, which takes continuous values between 0 and 1 , rather than the binary function $g$ leads to a nonlinear programming (NLP) problem and avoids a mixed-integer nonlinear programming (MINLP) formulation, whose complexity would be much higher. 


\section{RESULTS}

In this section, the simulation scenarios and results are presented.

\section{A. Simulation scenarios}

Three traffic scenarios are defined

1) Uncontrolled baseline: the accesses from the periurban to the urban area are permanently open. The speed limits are constantly equal to $70 \mathrm{~km} / \mathrm{h}$ in the peri-urban area and $50 \mathrm{~km} / \mathrm{h}$ in the urban area.

2) Controlled VSL: the accesses from the peri-urban to the urban area are permanently open. The speed limits are constantly equal to $70 \mathrm{~km} / \mathrm{h}$ in the peri-urban, but they are dynamically optimized in the urban area, taking continuous values between $20 \mathrm{~km} / \mathrm{h}$ and $50 \mathrm{~km} / \mathrm{h}$.

3) Controlled access: the accesses from the peri-urban to the urban area are controlled, but the speed limits are constant over the simulation duration $(70 \mathrm{~km} / \mathrm{h}$ in the peri-urban area and $50 \mathrm{~km} / \mathrm{h}$ in the urban area).

To satisfy the Courant-Friedrichs-Lewy (CFL) [20] condition, the time step duration $\delta_{t}$ is set to $1 \mathrm{~s}$. The control and prediction horizons of the NMPC strategy are respectively $T_{\text {cycle }}=1 \mathrm{~min}$ and $T_{\mathrm{p}}=5 \mathrm{~min}$. The weighting coefficient $\lambda$ is set to 0.7 in order to privilege the environmental sustainability in the urban area as it is supposed to be denser with more traffic.

In the urban area, all roads are one-way, of equal length and capacity. At each intersection, both downstream roads have the same split ratio $\beta_{i}=0.5$.

We consider a simulation of duration $T=1 \mathrm{~h}$ during which the exogenous demand is set at $d^{\text {in }}=0.2 \mathrm{veh} / \mathrm{s}$ and the intermittent endogenous demand is

$$
d_{i}(k)= \begin{cases}0.1 \mathrm{veh} / \mathrm{s}, & \text { if } 6 \mathrm{~min} \leq k \leq 9 \mathrm{~min} \\ 0.1 \mathrm{veh} / \mathrm{s}, & \text { if } 31 \mathrm{~min} \leq k \leq 34 \mathrm{~min} \\ 0 \mathrm{veh} / \mathrm{s}, & \text { otherwise }\end{cases}
$$

\section{B. Simulation results}

The results of the three scenarios defined in Section IV-A are summarized in Fig. 4. The fuel consumption, the $\mathrm{NO}_{\mathrm{X}}$ emissions, and the TTD are calculated using the data of the microscopic traffic simulator SUMO and the microscopic physical energy and $\mathrm{NO}_{\mathrm{X}}$ models.

The average fuel consumption and $\mathrm{NO}_{\mathrm{X}}$ emissions presented in Fig. 4a \& 4b indicate that the VSL controller is able to improve the energy efficiency both in the urban $(18 \%)$ and in the peri-urban $(14 \%)$ areas. Similar results are observed with $\mathrm{NO}_{\mathrm{X}}$ emissions, which are reduced by $18 \%$ in the urban area and by $13 \%$ in the peri-urban area. However, the access control approach only allows to improve the environmental sustainability in the urban area (fuel consumption reduced by $7 \%$ and $\mathrm{NO}_{\mathrm{X}}$ emissions reduced by $6 \%$ ) in exchange for a deterioration of the performances in the peri-urban area (fuel consumption increased by $21 \%$ and $\mathrm{NO}_{\mathrm{X}}$ emissions increased by $19 \%$ ). (a) Average fuel consumption.

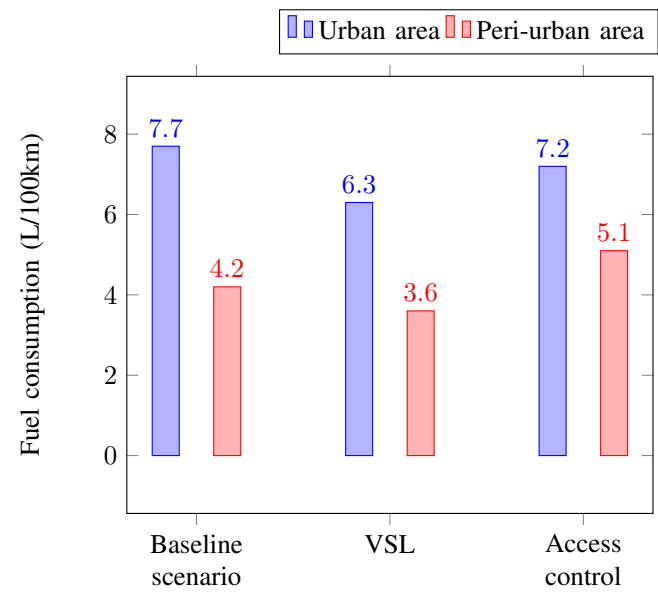

(b) Average $\mathrm{NO}_{\mathrm{X}}$ emissions.

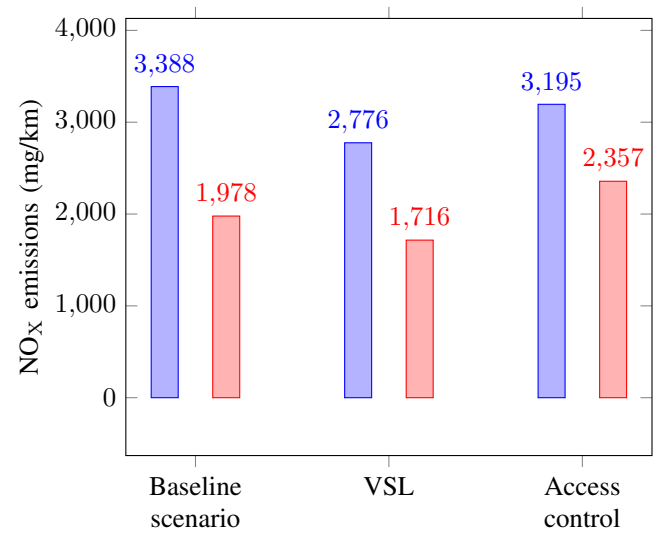

(c) Total travel distance.

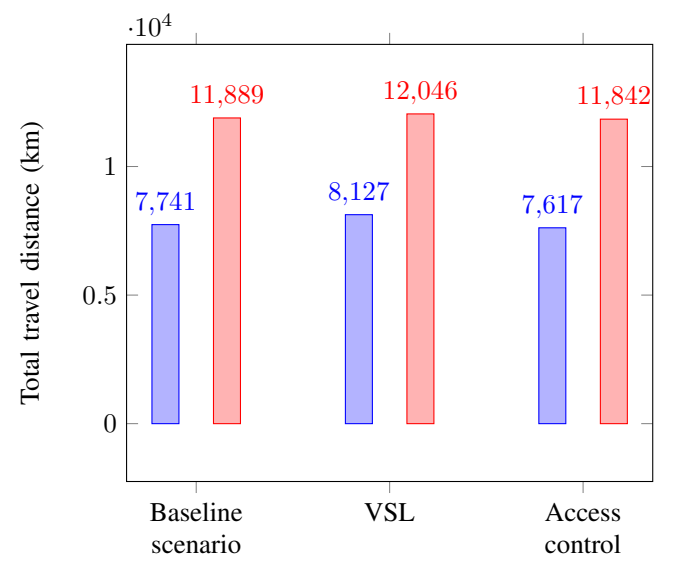

Fig. 4: Comparison of the energy efficiency, pollutant emission level, and traffic performance in the baseline, the VSL, and the controlled access scenarios.

Fig. 4c reveals that the impact of both controllers on the TTD is lower, which is conceivable because it is not explicitly the optimization criterion. The VSL controller improves it both in the urban $(5 \%)$ and in the peri-urban (1\%) areas. The access control approach deteriorates it in the urban area $(2 \%)$ and does not affect it in the peri-urban 
area.

As a result, the VSL controller is more appropriate in this study because it gives better results in both areas in terms of energy efficiency, pollutant emissions, and traffic performance. In practice, both controllers aim at reducing the inflow in the urban area during peak times because the congestion deteriorates the energy efficiency. The difference is that the access control is much more discriminating towards vehicles in the peri-urban area as it forces them to stop and start, which is very energy consuming. On the other hand, the VSL controller leads to smoother density variations.

\section{CONCLUSION}

In this work, an NMPC approach has been employed to compare the effect on energy efficiency of two control actuators, namely the speed limits and the signalized access actuators. For the chosen parameterization and synthetic tworegion network of intermediate size, it appears that the VSL approach is more efficient. In fact, it reduces the global fuel consumption up to $18 \%$ in the urban area, against $7 \%$ for the access control which also decreases the performance in the peri-urban area. The reason is that VSLs leads to smoother density variations, which are more energy-efficient.

To go further, a scalability analysis with more complex and asymmetrical road networks could be of particular interest, especially in scenarios that combine the benefits of both actuators.

\section{REFERENCES}

[1] S. Heft-Neal, J. Burney, E. Bendavid, and M. Burke, "Robust relationship between air quality and infant mortality in africa," Nature, vol. 559, no. 7713, pp. 254-258, 2018.

[2] A. Font, L. Guiseppin, M. Blangiardo, V. Ghersi, and G. W. Fuller, "A tale of two cities: is air pollution improving in paris and london?," Environmental Pollution, vol. 249, pp. 1-12, 2019.

[3] B. Othman, G. de Nunzio, A. Sciarretta, D. Di Domenico, and C. C. de Wit, Connectivity and Automation as Enablers for Energy-Efficient Driving and Road Traffic Management. Springer New York, 2021.

[4] S. Quarmby, G. Santos, and M. Mathias, "Air quality strategies and technologies: A rapid review of the international evidence," Sustainability, vol. 11, no. 10, p. 2757, 2019.

[5] L. Tumash, C. Canudas de Wit, and M. L. Delle Monache, Boundary and VSL Control for Large-Scale Urban Traffic Networks, 2021. Working paper or preprint, available at https://hal. archives-ouvertes.fr/hal-03167733.

[6] M. Tajali and A. Hajbabaie, "Dynamic speed harmonization in urban street networks," Computer-Aided Civil and Infrastructure Engineering, 032018.

[7] M. Van den Berg, A. Hegyi, B. De Schutter, and H. Hellendoorn, "Integrated traffic control for mixed urban and freeway networks: A model predictive control approach," European Journal of Transport and Infrastructure Research EJTIR, 7 (3), 2007.

[8] M. Madireddy, B. De Coensel, A. Can, B. Degraeuwe, B. Beusen, I. De Vlieger, and D. Botteldooren, "Assessment of the impact of speed limit reduction and traffic signal coordination on vehicle emissions using an integrated approach," Transportation research part D: transport and environment, vol. 16, no. 7, pp. 504-508, 2011.

[9] B. Khondaker and L. Kattan, "Variable speed limit: an overview," Transportation Letters, vol. 7, no. 5, pp. 264-278, 2015.

[10] B. Othman, G. De Nunzio, D. Di Domenico, and C. Canudas-de-Wit, "Variable speed limits control in an urban road network to reduce environmental impact of traffic," in 2020 Annual American Control Conference (ACC), pp. 1179-1184, IEEE, 2020.
[11] J. Haddad and N. Geroliminis, "On the stability of traffic perimeter control in two-region urban cities," Transportation Research Part B: Methodological, vol. 46, no. 9, pp. 1159-1176, 2012.

[12] I. I. Sirmatel and N. Geroliminis, "Stabilization of city-scale road traffic networks via macroscopic fundamental diagram-based model predictive perimeter control," Control Engineering Practice, vol. 109, p. 104750, 2021.

[13] C. F. Daganzo, "The cell transmission model: A dynamic representation of highway traffic consistent with the hydrodynamic theory," Transportation Research Part B: Methodological, vol. 28, no. 4, pp. 269-287, 1994.

[14] M. J. Lighthill and G. B. Whitham, "On kinematic waves ii. a theory of traffic flow on long crowded roads," Proceedings of the Royal Society London A, vol. 229, no. 1178, pp. 317-345, 1955.

[15] P. I. Richards, "Shock waves on the highway," Operations Research, vol. 4, no. 1, pp. 42-51, 1956.

[16] S. Zegeye, B. De Schutter, J. Hellendoorn, E. Breunesse, and A. Hegyi, "Integrated macroscopic traffic flow, emission, and fuel consumption model for control purposes," Transportation Research Part C: Emerging Technologies, vol. 31, pp. 158-171, 2013.

[17] P. A. Lopez, M. Behrisch, L. Bieker-Walz, J. Erdmann, Y.-P. Flötteröd, R. Hilbrich, L. Lücken, J. Rummel, P. Wagner, and E. Wießner, "Microscopic traffic simulation using sumo," in The 21st IEEE International Conference on Intelligent Transportation Systems, IEEE, 2018.

[18] M. Treiber, A. Hennecke, and D. Helbing, "Congested traffic states in empirical observations and microscopic simulations," Physical review $E$, vol. 62, no. 2, p. $1805,2000$.

[19] L. Thibault, P. Degeilh, O. Lepreux, L. Voise, G. Alix, and G. Corde, "A new gps-based method to estimate real driving emissions," in 2016 IEEE 19th International Conference on Intelligent Transportation Systems (ITSC), pp. 1628-1633, 2016.

[20] R. Courant, K. Friedrichs, and H. Lewy, "On the partial difference equations of mathematical physics," IBM journal of Research and Development, vol. 11, no. 2, pp. 215-234, 1967. 